\title{
The Product Space Revisited: China's Trade Profile
}

\author{
Benno Ferrarini $\dot{H}^{\dagger}$ and Pasquale Scaramozzino* \\ + Economics and Research Department, Asian Development Bank \\ * Department of Financial and Management Studies, SOAS, University of London, \\ and Dipartimento di Economia Diritto e Istituzioni, Università di Roma Tor Vergata
}

Submitted: 10 August 2011

Revised: 5 December 2013

\section{INTRODUCTION}

Countries' production capabilities have long been considered a driver of long-term growth. In pioneering work, Hirschman (1958) showed capabilities to depend mainly on the existence of backward and forward linkages across products, in turn reflecting complex interactions between economies of scale and market size. More recently, Sutton (2001) argued that the success of modern industrialized economies ultimately rests on networked firms that enjoy the benefits of scarce capabilities. These are broadly defined as the working practices or know-how that make it possible to achieve high levels of quality or productivity. Such countries are therefore able to specialize in lucrative, high-wage activities which directly contribute to their long-run growth prospects and which are the main determinants of differences in the wealth of nations. Positive externalities from clustering and input-output linkages across manufacturing firms are then responsible for the regional concentration of capabilities, consistent with the literature on geography and trade (Fujita, Krugman and Venables, 1999). Related to this is the literature on market structure, which argues that only a small number of leading firms can manage to gather sufficient clout to capture global markets (Sutton, 1998).

Because of capabilities' complex and largely latent nature, direct measurement has not been possible. Only recently have Hausmann and Klinger (2006) proposed an indirect measure of capabilities, based on the notion that a country's productive structure can be deduced from its 
observed profile of trade specialization. This approach is consistent with traditional trade theory relating trade specialization to resource endowments and available technology. The authors combine countries' international export data by products to obtain a representation of the product space that describes the global pattern of revealed comparative advantage. Relating a country's export profile to its location within this product space, inference is made about its scope to expand into new export products on the grounds of the production capabilities attributed to its current specialization profile.

Hidalgo, Klinger, Barabási and Hausmann (2007) apply the tools of complex network analysis to visualize the product space as maps of relative product proximities. Hausmann, Hwang and Rodrik (2007) further show that countries' export structure and relative position within the product space explain differences in growth performance in a cross-section of countries. A country's current position within the product space is thus proposed as a leading indicator of its development prospects.

Despite the considerable resonance this line of research has had in applied development work ${ }^{1}$, it does not appear to have undergone much scrutiny in the subsequent economics literature. Yet it would appear that its main premise - that countries' capabilities can be deduced on the grounds of gross export values alone - may not be fully consistent with an established body of theoretical and empirical research emphasizing the important role of intra-industry trade in explaining global trade patterns. ${ }^{2}$ More specifically, a substantial share of world trade is known to take place within rather than between production sectors. ${ }^{3}$ Such trade is partly explained by horizontal product differentiation, where otherwise similar products are distinguishable according to certain taste attributes or varieties. A similarly large share of intra-industry trade is characterized by differentiation among products of similar variety but of distinct quality. Roughly put, horizontal intra-industry trade constitutes the bulk of trade among countries at a similar level of development, such as within the European Union, whereas the existing evidence associates lower product quality mainly with the exports of countries at lower levels of income (Schott, 2004).

\footnotetext{
${ }^{1}$ The Asian Development Bank, jointly with the International Labor Organization and the Islamic Development Bank, has been applying the product space approach as one of the tools of its Country Diagnostics Studies (ADB-ILO-IDB, 2010).

${ }^{2}$ See, for instance, Shaked and Sutton (1984); Sutton (1986); Greenaway and Torstensson (1997); Greenaway and Milner (2003); Fontagné, Freudenberg and Gaulier (2006).

${ }^{3}$ Brülhart (2009) estimates that, in 2006, 44 percent of global trade was intra-industry at the 3-digit level of disaggregation, and 27 percent was intra-industry at the 5-digit level of disaggregation.
} 
Failure to account for intra-industry trade in product space analysis undermines a more accurate representation of specialization patterns observed in world trade and distorts the attribution of capabilities according to countries' observed specialization. In particular, the exclusive reliance on export values precludes accounting for trade in product varieties as can be deduced from products' net exports and unit values. Taking into account net trade and unit values is thus likely to profoundly affect the key aspects of the product space, both with regard to its clustering of products according to relative proximities across product variety and quality and the assessment of countries' position in the space. Of particular interest are the implications with regard to the emerging economies that have arisen to dominate large shares of world trade in recent decades. China, notably, is found to have substantially diversified its export structure, which accelerated since its 2001 WTO accession (Baldwin, 2012). In terms of the reflections on Chinas' occupancy of the product space, however, analytically relevant is not just the assessment of the country's shifts into previously unoccupied export products, but also the extent to which it has managed to evolve its trade profile into product varieties and qualities as its GDP per capita expanded and its role as a global export hub increased.

This paper extends product space analysis in two directions. To incorporate horizontal intraindustry trade, the exports-based indicator of Revealed Comparative Advantage (RCA) is replaced by an indicator based on net exports at the product level. To account for the quality of goods traded within industries, unit-value ( $U V$ ) distributions are used to distinguish countries according to whether they trade in the high- or low-quality product variety. As a result, our analysis includes two dimensions identifying an economy's ability to expand its production and trade structure: horizontally, by moving to products in the product space that are within its reach, and vertically, by climbing up the $U V$ ladder within or across products lines.

This marks a fundamental departure from the bi-dimensional nature of product space as defined by Hausmann and Klinger (2006). By adding the unit-value dimension, inference can be made about the suitability of any country's set of capabilities to move vertically within the unit-value space, on top of horizontal movements. This appears particularly relevant to gauging countries' capabilities, as existing evidence points to a close association of low-income countries with the export of low-UV products (Schott 2004). It could thus be expected that vertical unit-value, rather than just horizontal 
constraints to movements by countries are present within the product space. Moreover, the combination of horizontal and vertical unit-value constraints to countries' productive adaptability are likely to compromise the feasibility of diagonal movements within the product space, as for example from the low-UV segments of one product to the high-UV segments of another.

Ample evidence of considerable variation in unit values across countries is shown by Fontagne' et al. (2008). Building on Schott (2004), they demonstrate that the apparent similarity of exports of advanced and developing countries (North and South, in their terms) is much reduced when a comparison is made at the level of products rather than industries, and even more so at the level of unit value analysis, to distinguish varieties within product categories. They conclude that, although some developing countries are now in competition with the advanced countries on a wide range of products - in 2004, China exported 4932 out of 5041 products traded at the international level — the varieties of products exported by these two groups of countries appear too different to be in direct competition.

Schott (2008) echoes these findings in his assessment within product markets of China's competition with the advanced economies. He confirms that China's and OECD countries' exports overlap extensively, which he argues can be explained by China's size and ability to produce and export broader ranges of goods, notwithstanding a comparably lower level of development. He also finds that China's presence in the product markets has increased over time, from $9 \%$ of all manufacturing product categories in 1972 , to $85 \%$ of all categories in 2005 . However, Schott demonstrates that the picture changes when variation in unit values (i.e. export prices) hence product variety is accounted for; China exhibits manufactures and machinery export prices that are on average 40 to $60 \%$ lower than for the OECD countries from 1980 to 2005 .

The analyses in Fontagne' et al. (2008) and Schott (2008) are both concerned mainly to infer upon the impact of competition from developing countries, and China in particular, on labor markets in the advanced countries. Export of different product varieties, they argue, stems against or at least qualifies widely felt fears in advanced countries' labor markets about strong and increasing competition from low-cost origins like China having been eroding jobs and wages at home. Our paper instead extends the insights from unit value analysis to an upgraded version of the product space, 
which is also enhanced to reflect intra-industry trade. The extended product space is then applied to the assessment of the space occupancy by China and the U.S., compared to that in the original Hausmann-Klinger (2006) approach.

It should be noted that the analysis in this paper, albeit reflective of intra-industry and unitvalue trade falls short of fully taking into account the vertical nature of trade in parts and components and services associated with the international fragmentation of production. Such trade has become more prominent during the past three decades, with the progressive integration of world markets and the fragmentation of production across countries, and consequently the formation of global supply chains. As different stages of production are often performed in different countries, the associated cross-border trade in parts, components, intermediate goods and services—or 'supply-chain trade' 4 as it is often referred to- has come to predominate world merchandise trade (Arndt and Kierzkowski, 2001; Athukorala and Yamashita, 2006). This has increasingly involved China, which in the mid 2000s rose to take central position of what has become known as 'factory Asia', a complex production network spanning across the East Asian countries, mainly in relation to the Information and Communication Technologies (ICT) and automotive industries (Baldwin, 2006 and 2012).

The recent release of multi-regional input-output tables - such are the World Input Output Database (WIOD) in 2012 and the OECD-WTO Trade in Value Added (TiVA) database in 2013has significantly improved our capacity to measuring the phenomenon of vertical trade links across industries and countries. However, few developing countries and less than 60 industries are covered by these data, which is unsuitable for the finely disaggregated level of product space analysis, involving several thousands of products. Nevertheless, the approach promoted in this paper is suitable to capturing the horizontal dimension of intra-industry trade, as well as portions of supply-chain trade, to the extent that such trade occurs within the same product category as final goods trade. This will be the case for some of the trade in electric and electronics intermediates. Conversely, trade in auto parts and final assembly has been shown to scatter across a broader range of product categories, and an association of intermediates with final goods trade will be missed out on almost entirely by the

\footnotetext{
${ }^{4}$ This type of trade appears under different names in the literature, including vertical trade, network trade, processing trade, and supply chain trade. In this paper, we adopt the term "supply-chain trade", to keep it distinct from the "vertical" nature of unit value analysis.
} 
intra-industry measure's reliance on product-level net trade statistics alone (Ferrarini, 2013). As a result, our intra-industry product space will overestimate a country's capabilities to the extent that they are reflective of imported parts and components, such as the processor, monitor, display and most of the other key electronic components embodied in an IPod assembled and exported by China to end consumers around the world (Dedrick et al. 2010). Removal of this bias in product space analysis hinges upon the public availability in future of finely disaggregated input-output tables or industry data that would fully reflect global value chain trade, opening up important avenues of future expansion upon the analysis in this paper.

The paper is structured as follows. Section 2 outlines the Hausmann-Klinger (2006) product space and our enhancements for it to reflect intra-industry trade and unit value analysis. Section 3 computes the enhanced product space and compares its features with those of the original approach. Particular focus will be given to the implications for China. Section 4 draws the conclusions and sketches out some of the issues for further research.

\section{PRODUCT SPACE WITH INTRA-INDUSTRY TRADE}

In a series of contributions, Hausmann and Klinger (2006, 2007), Hausmann, Hwang and Rodrik (2007), Hidalgo, Klinger, Barabási and Hausmann (2007), Hidalgo and Hausmann (2009) and Hidalgo (2009) develop an appealingly simple method to establish the proximity of globally traded products according to the intrinsic production capabilities they embody. Proximity between any pair of products is defined according to the relative frequency with which they are jointly exported by countries having a revealed comparative advantage in those specific product categories. Products that countries export jointly are assumed to be reflective of the production capabilities of those exporting countries. After extrapolating production capabilities for all products according to the observed pattern of dyadic joint exports across countries, a country's relative position within the full set of product proximities is taken as a metric according to which its comparative production capabilities can be established, jointly with its potential to move into product categories which it has not yet occupied according to its revealed export profile. 
Central to this approach and its assessment of trade specialization is Balassa's (1986) index of Revealed Comparative Advantage (RCA), which relates a product's weight in a country's export basket to its weight with respect to some reference area, typically the world. Based on the RCA is the notion of capabilities, with respect to a country's opportunity to shift production and exports toward commodities it does not yet produce but which are deemed within reach on the grounds of the production and structure it currently displays. Two products are regarded as proximate in terms of the production capabilities they require when comparative advantage in one product tends to be associated with comparative advantage in the other and vice versa, based on the observed exports patterns across all countries. Depending on whether or not two goods are found to be exported jointly by countries with a RCA in these goods, an indicator for trade specialization in relation to any good $j$ is defined as:

$$
w_{c, i}=\mathrm{I}\left(R C A_{c, i} \geq 1\right) \equiv\left\{\begin{array}{l}
1 \text { if } R C A_{c, i} \geq 1 \\
0 \text { if } R C A_{c, i}<1
\end{array}\right.
$$

An index of proximity between goods $i$ and $j$ is then obtained from the conditional probability that countries specializing in the production of one commodity also specialize in the production of the other commodity, or $\left.\mathrm{P}\left(w_{c, i}\right)=1 \mid w_{c, j}=1\right)$. Specifically, the index of proximity $\varphi(i, j)$ is defined as ${ }^{5}$ :

$$
\varphi_{i, j}=\min \left\{\mathrm{P}\left(w_{c, i}=1 \mid w_{c, j}=1\right), \mathrm{P}\left(w_{c, j}=1 \mid w_{c, i}=1\right)\right\}
$$

The index of proximity between commodities $i$ and $j$ thus captures commodities' distance in the product space according to their joint profile of revealed comparative advantage. In turn, products' proximity is a measure of their "closeness" and relates to countries' ability to shift production from one into another on the basis of the pool of capabilities they have accumulated.

In each country $c$, the subset of products close to any given product $i$ can be measured by the proportion of all paths leading to that product in which country $c$ is present (Hausmann and Klinger, 2006). This can be interpreted as the average proximity of a new potential product to a country's current productive structure. The higher is the density mass around a given product, the easier it

\footnotetext{
${ }^{5}$ See Hausmann and Klinger (2006) for a discussion of the use of this measure of proximity between products.
} 
would be for the country to adapt to the production of new products. Formally, the index of density of product $i$ for country $c$ is defined as:

$$
\omega_{c, i}=\frac{\sum_{j} \varphi_{i, j} w_{c, j}}{\sum_{j} \varphi_{i, j}}
$$

A graphical description of the density of products according to their relative proximity is given by the product space. Hausmann and Klinger (2006) compare the product space with a forest, the trees of which can be thought of as representing different products. Proximity is then a measure of how close trees stand to each other, and a country's capacity to adapt to the production of a new commodity is akin to a forest monkey's ability to hop from one tree to another. The closer the trees or products, the easier it will be for a country to adjust extant capabilities to move into new lines of production. It follows that a country draws an advantage from being located in a relatively "dense" region of the product space, in terms of its capacity to branch out to new products. We amend the product space in two respects: by (i) substituting the Balassa indicator for a RCA indicator that reflects horizontal intra-industry trade, and (ii) by using product-level unit-value $(U V)$ distributions across countries (ie. world-wide) to distinguish countries according to whether they trade in the highor low-quality product varieties. Specifically, we adopt the Lafay (1992) indicator as a RCA measure that accounts for horizontal intra-industry $\operatorname{trade}^{6}$ :

$$
L F_{c, i}=\left(\frac{x_{c, i}-m_{c, i}}{x_{c, i}+m_{c, i}}-\frac{X_{c}-M_{c}}{X_{c}+M_{c}}\right) \frac{x_{c, i}+m_{c, i}}{X_{c}+M_{c}}
$$

where $X_{c}=\sum_{i} x_{c, i}$ and $M_{c}=\sum_{i} m_{c, i}$ are total exports and imports of country $c$ respectively. In contrast to the Balassa index, $L F$ establishes RCA on the grounds of trade balances, not exports, and it does so by relating a product's weight to a country's own trade balance overall, not with respect to a specific reference area.

The indicator function for trade specialization can now be defined with respect to the Lafay index $L F$ :

\footnotetext{
${ }^{6}$ Equation (4) coincides with the indicator used by Bugamelli (2001). Also see Zaghini (2005) and Alessandrini, Fattouh, Ferrarini and Scaramozzino (2011) for examples of applications of this indicator.
} 


$$
q_{c, i}=\mathrm{I}\left(L F_{c, i} \geq 0\right) \equiv\left\{\begin{array}{l}
1 \text { if } L F_{c, i} \geq 0 \\
0 \text { if } L F_{c, i}<0
\end{array}\right.
$$

The index of proximity (2) must be accordingly modified as:

$$
\theta_{i, j}=\min \left\{\mathrm{P}\left(q_{c, i}=1 \mid q_{c, j}=1\right), \mathrm{P}\left(q_{c, j}=1 \mid q_{c, i}=1\right)\right\}
$$

The proximity index $\theta_{i, j}$ is used for the computation of the product space in terms of net trade flows in Section 3.

Finally, unit values are introduced to the analysis according to the cumulative distribution function of $F$ of the unit values within each of the product categories, distinguishing a high-UV and a low-UV segment of the UV distribution separated by its median value $U V m$ :

$$
i \rightarrow i^{l} \text { if } U V^{i} \leq U V_{m}^{i} \quad \text { and } \quad i \rightarrow i^{h} \text { if } U V^{i} \geq U V_{m}^{i}
$$

Similarly to the bi-dimensional case, proximity is defined across product categories, now with the additional distinction between high-UV and low-UV subcategories:

$$
\theta_{i^{l, h}, j^{l, h}}=\min \left\{\mathrm{P}\left(q_{c, i^{l, h}}=1 \mid q_{c, j^{l, h}}=1\right), \mathrm{P}\left(q_{c, j^{l, h}}=1 \mid q_{c, l^{l, h}}=1\right)\right\}
$$

\section{IMPLEMENTATION OF THE INTRA-INDUSTRY PRODUCT SPACE}

The empirical analysis of trade flows is carried out on the CEPII-BACI dataset. ${ }^{7} \mathrm{BACI}$ covers over 5,000 products, which are aggregated according to the Harmonized System 1996 nomenclature (HS96). For the revised analysis of product space in this paper, we make use of value and unit value data from the year 2007 for 144 countries at the four (HS4) and six (HS6) digits levels of aggregation. ${ }^{8}$ For comparison, revealed comparative advantage is measured both in terms of the Balassa (1986) and of the Lafay (1992) indices. For each product category the median $U V$ is computed across all trade partners, and individual countries are classified as either high or low-UV

\footnotetext{
${ }^{7}$ Base pour l'Analyse du Commerce International (BACI) data is based on the UN COMTRADE database, which is mirrored and gap-filled to achieve a complete and consistent data series of value and volume data across countries. BACI is maintained by the Centre d'Etudes Prospectives et d'Informations Internationales (CEPII). See Gaulier and Zignago (2010) for a detailed description of the database.

${ }^{8}$ In a strict sense, computing unit values at 4 digits of the HS classification does not necessarily reflect product varieties, as this level of aggregation typically subsumes different products. Nevertheless, unit values at the 4-digit level provide a measure of relative prices that is relevant for product space analysis and for comparison with the results of the Hausmann-Rodrik (2006) analysis..
} 
with respect to a specific product according to whether their UV is found to be higher or lower than the cross-country median, according to equation (7).

Products are classified by an index of productivity or product sophistication, following Hausmann, Hwang and Rodrik (2007). The index represents the average per capita GDP embodied in goods traded, and is derived as the sum across all commodities of the product of the index of comparative advantage $R C A_{c, i}$ by the average per capita income of exporting countries. The resulting productivity index, or $P R O D Y_{i}$, is thus computed as:

$$
\operatorname{PRODY}_{i}=\sum_{c} R C A_{c, i} \cdot Y_{c}
$$

To satisfy our analysis' requirement for a highly detailed product classification, up to 6 digits HS, we adopt the PRODY indicator in lieu of alternative classifications, such as the widely used Leamer categories. ${ }^{9}$ The $P R O D Y$ index is used throughout the subsequent analysis in order to classify products and country trade profiles according to productivity quartiles. According to equation (9) a product $i$ will be assigned the highest PRODY quartile if it is traded with comparative advantage by countries within the highest income per capita quartile. By the same token, a country occupying the product space where the highest-quartile $P R O D Y$ products are located is taken as resembling the typical trade profile of the highest-quartile income-per-capita countries.

Table 1 breaks down the Balassa's RCA index by unit value and by quartiles of the PRODY distribution for the whole sample, including 144 countries, and specifically for China and the US. ${ }^{10}$ To compute PRODY across countries and products, we take GDP per capita at purchasing power parity and constant 2005 US\$, combined with CEPII trade flows taken at 2006/2007 average. Table 1 shows that across all countries, average Balassa RCA is a decreasing function of both $U V \mathrm{~s}$ and of PRODY. In other words, global trade is more prevalent in goods with lower UVs and lower PRODY. For individual countries, the RCA distribution changes, in favor of low UVs in the case of China, and with an equal distribution of low and high UVs for the US. Equally revealing is the distribution of the RCA according to PRODY quartiles, which indicates that specialization is strongest for products

\footnotetext{
${ }^{9}$ Leamer (1984) splits products into ten categories, such as capital-intensive and resource-intensive goods. However, these categories are defined according to 2-digit SITC classification, which does not provide the disaggregation that would be necessary for its use in this analysis.

${ }^{10}$ The empirical work for this paper encompasses a detailed analysis of all the 144 countries included in the dataset. For reasons of space and focus, only results in relation to China and to a lesser extent the United States are presented in greater detail.
} 
associated with the lowest PRODY quartile. This can be explained by the prevalence among lowincome countries of specialization in a few primary commodities. Indeed, the degree of specialization quickly drops as $P R O D Y$ increases, down to 1.26 average in the fourth quartiles.

For the case of China, Table 1 shows increasing specialization when moving from the first to the second quartile, indicating that the country's trade profile has moved far beyond that associated with countries falling within the lowest quartile of per-capita GDP. However, the RCA is shown to fall by about a sixth when moving from the second to the third quartile of PRODY, and it drops considerably in relation to highest quartile. Overall, China's trade profile appears to be concentrated mainly in products associated with the first three quarters of the PRODY scale, but not yet in those products typically associated with the most affluent among trading countries. This is the case of the US, the trade specialization of which is shown to increase with higher quartiles of PRODY, and is highest for those products associated with the fourth quartile of $P R O D Y$.

Next we compute the Lafay index for all countries and all products, according to equation (4). It should be noted that the Lafay index by construction takes zero as its mean, hence a summary table as for the Balassa-based results in Table 1 is not particularly revealing. Instead, Table $2 \mathrm{a}$ reports correlation coefficients between the two RCA indicators in relation to the full sample of countries, broken down by UV and PRODY categories. A Pearson coefficient of only 0.1399 shows that the two indicators correlate only weekly across countries and products, and that correlation is particularly weak among high- $U V$ s products and among products within the second-quartile of PRODY. The Spearman rank correlation yields higher coefficients compared to Pearson, but a 0.525 average sample correlation between Balassa and Lafay RCA indicates a relatively moderate degree of correlation between the indicators. Table $2 \mathrm{~b}$ indicates that Spearman correlation is higher for individual countries, particularly when based on the less disaggregated HS4 data set. Overall, however, preliminary correlation analysis would suggest that the choice of indicator will have profound implications on the product space analysis to follow.

Figures 1a-b plot the cumulated Lafay and PRODY indices for China and the USA, based on the analysis at four digits of HS. Products are ordered on the horizontal axis by increasing values of the productivity index $P R O D Y$. Increasing values of the cumulated Lafay denote trade specialization 
over the range of products covered, whereas decreasing values of the cumulated graph indicate trade despecialization. The upward-sloping section of the Lafay line shows China to be specializing in lowand intermediate-PRODY items, whereas the opposite (despecialization) appears to be the case for high-PRODY products. By contrast, the US can be seen despecializing in relation to products within the lower sections of the PRODY distribution and by a pronounced specialization in the upper segments.

Product space analysis in Hidalgo et al. (2007) owes much of its appeal to the visual network analysis and graphs, which has helped popularizing its key findings to the broader public and to key stakeholders, such as developing country government agencies and the global and regional development institutions. To allow for a visual comparison with the enhanced product space proposed in this paper, we rely on Cytoscape (Shannon et al., 2003), an open-source platform for complexnetwork analysis. ${ }^{11}$ The layout of the space is achieved through the application of an iterative springembedded algorithm, which sorts through the whole set of product proximities computed at 4 digits HS. This yields a clustering of nodes (products) according to the relative intensities of the connecting edges (proximities). To achieve a rendition of the product space that is comparable to that of Hidalgo et al. (2007), we drop proximities smaller than 0.60 and color-code products (nodes) according to the PRODY distribution, with quartiles as delimiters (percentiles no. 25, 50, and 75). Products with low per-capita GDP are colored green, the next-higher quartiles are light blue, dark blue, and red, respectively. To differentiate products' weight in world trade, the relative size of the nodes is made reflective of their total value shares.

Figures $2 \mathrm{a}$ and $2 \mathrm{~b}$ show the Balassa-based product space, akin to the original approach in Hidalgo et al. (2007). Figures 3a and 3b show the product space based on Lafay-RCA. China's and US' presence within both the product spaces is marked by nodes taking a triangular instead of a round shape. More markedly than in the Balassa-based graph, where products appear to be distributed more densely and uniformly, the Lafay space emphasizes the difficulties countries face when trying to diversify their trade away from products associated with the bottom two quartiles of the PRODY distribution and into to the upper two quartiles. Indeed, when horizontal intra-industry trade is duly

\footnotetext{
${ }^{11}$ Also see www.cytoscape.org.
} 
accounted for, the product space appears strongly dichotomized into two halves, roughly delineating a separation of products according to which below-median PRODY products are allocated in the bottom halve of the map, and above-median PRODY products are in the upper halve. ${ }^{12}$

In both the Balassa and the Lafay space, China is shown to occupy mainly the product categories associated with lower GDP per capita, whereas the opposite holds true for the US. ${ }^{13}$ Both the spaces provide evidence that China has broken through the median barrier, with a trade profile that is well presented in the third quartile of the PRODY distribution. That is, even when intra-industry trade is duly accounted for, China's presence in the upper section of the Lafay space provides testimony to its successful crossing the thin bridge separating the trade profile of countries with above-median GDP per capita from those which lie below (Figure 4a). However, at least in part, China's occupancy of the upper section of the Lafay space is qualified by the likely bias deriving from our intra-industry measure's inability to fully capture China's central role within the Asian production networks. As an assembler of imported parts and components, China's exports embody foreign capabilities that go undetected in the intra-industry net trade measures but which likely play a significant part in explaining China's occupancy of the space that pertains to the source countries of those imported capabilities.

China's trade profile remains to be assessed in the three-dimensional product space, by distinguishing within-product differentiation according to unit value distributions. The rendition in print of a three-dimensional product space is problematic, hence we represent its main features as cumulative plots of the Lafay index, which are now drawn separately for low unit values (Figure 4a) and for high unit values (Figure 4b) in relation to China. Since unit value data are available for all the products in the data set, the cumulative graphs reflect China's position across the entire product space. Product codes are now separated into high- and low- $U V$, according to whether China's net exports position as measured by the Lafay $R C A$ falls above or below the median of the $U V$ distribution in relation to any specific product (equations 7 and 8).

\footnotetext{
${ }^{12}$ At the 0.60 cut-off value of proximity shown in Figures $3 a$ and $3 b$, the only connection between the upper and lower spheres of the Lafay space is between product category 7309 (Tanks etc., over 300 Liter Capacity, Iron or Steel) and category 9406 (Prefabricated Buildings). ${ }^{13}$ Of course, this is in line with the evidence presented above, in particular see Figures 1a and $1 \mathrm{~b}$.
} 
The evidence with respect to China is striking. Across the entire array of products sorted according to increasing PRODY, China can be seen to specialize exclusively in low $U V \mathrm{~s}$ (Figure 4a), while it is clearly despecialized in high- $U V$ products (Figure $4 \mathrm{~b}$ ). The opposite is true for the US: the country specializes in the market segment of high- $U V$ (Figure 5a) and the reverse is true for the segment of low- $U V$ products (Figure $5 \mathrm{~b}$ ). In terms of the product space analogy with a forest, China can thus be thought of as occupying exclusively the lower segments of the trees, whereas the US is present mostly in the tree tops. This strongly qualifies the earlier finding, in relation to the bidimensional space, about China having conquered all but the highest PRODY-segment. While this is certainly true in terms of China's horizontal occupation of the space, the UV analysis highlights that the country has still a long way to go in order for it to reach those higher sections of the trees preemptively occupied by affluent countries like the US. Put differently, along the vertical dimension of the product space, China is still broadly relegated to the low-UV sections, in reflection of its trade profile still being in line with that of a developing country.

Further implications of the vertical product space analysis emerges from Tables $3 \mathrm{a}$ and $3 \mathrm{~b}$, which relate average $U V$ proximities to inter-quartile distance in the productivity index PRODY. Proximities are computed according to equation 8, for data taken at 4 digits (Table 3a) and 6 digits (Table $3 \mathrm{~b}$ ). HH denotes that both products are high- $U V$ relative to the median, LL that both products are low- $U V$, and $\mathrm{HL}$ that one of the two products is high- $U V$ and the other is low- $U V .{ }^{14}$ Decreasing average proximity as inter-quartile distance increases confirms the earlier finding that products embodying similar levels of per-capita GDP are clustered together more closely in the product space. More relevantly, however, both the HS4 and HS6 analysis in relation to any given inter-quartile distance of $P R O D Y$ show that average proximity is lowest when one good is low-UV and the other is high-UV (the HL category). Put differently, the distance between products and with it a country's diversification constraints tend to be highest when they involve movements from the bottom of a product tree (low UV) to the top of another product tree (high UV) or vice versa.

\footnotetext{
${ }^{14}$ To derive this metric, $U V$ product categories are split according to the four quartiles of the PRODY distribution and inter-quartile differences between product pairs are then computed as absolute values. For instance, if Product A belongs to the third quartile and Product B to the first quartile of the PRODY distribution, the absolute difference takes value 2 . The difference measure is then tabulated against communality or not of $U V$ categories.
} 


\section{CONCLUSIONS}

This paper extends the product space analysis in two dimensions. First, it introduces an RCA indicator based on net trade flows as the central measure of analysis. The product space is thus made reflective of intra-industry trade, which the empirical trade literature has long identified as a main characteristic of global trade patterns. Second, the product space is computed on the basis of unit values and not just value data, which makes it reflective of within-product differentiation. Again, available evidence points to the importance for such distinction to be made in order for the product space to capture a central pattern of world trade, which sees low-income countries consistently associated with lower unit-value exports.

We set out with the expectation that these extensions to the product space would be found to have a profound impact on the assessment of proximities among product categories and thus the capabilities they are assumed to embody. This expectation was fully met by the evidence arising out of the product space revisions, which were computed on the basis of a detailed HS trade data set at four and six digits of product classification and spanning over 144 countries. We highlight three main findings.

First, the product space is highly sensitive to changes to its fundamental measure of RCA. The use of the Lafay measure of RCA, which rests on net trade flows to reflect intra-industry trade, profoundly alters the identification of products which countries trade in with comparative advantage. Such change in the central unit of measurement underlying the product space analysis significantly alters its gauge of product proximities and, by implication, any inference made with regard to the capabilities embodied by individual products.

Second, the product space incorporating horizontal intra-industry trade assumes highly distinctive features compared to the original, exports-based approach. Most notably, the modified space appears dichotomized into two halves with medium-level productivity as a rough line of separation between the two. Accounting for intra-industry trade in product space analysis thus emphasizes more strongly the difficulty for countries to migrate their production structures from lowto high-capability products. For the case of China, however, our analysis confirms the findings based on the original product space analysis. The country seems indeed to have firmly established itself to 
occupy the upper section of the product space, excluding only those products that are typically associated with the RCA profile of countries within the highest quartile of per capita GDP. The enhanced product space analysis thus emphasises China's achievements in expanding its trade profile by 2007, with only the highest $P R O D Y$ products for it left to conquer. As mentioned above, at least in part this finding is qualified by the likely bias deriving from our intra-industry measure's inability to fully capture China's central role within the Asian production networks. As an assembler of imported parts and components, China's exports embody foreign capabilities that go undetected in the intraindustry net trade measures.

Third, however, the introduction of a unit value dimension - through the differentiation of products according to their unit value distributions - sharply qualifies the findings and implications arising out of product space analysis, which cannot be evinced along the two dimensions of the original product space approach by Hausmann and Klinger (2006). In particular, a comparison between China and US in this UV-enhanced space shows a clear delineation of its occupancy by the two countries, with China's presence almost exclusively relegated to the low-UV products, and the US taking large sways of the high-UV segments. Notwithstanding China's horizontal conquests of the space, the country is shown to be facing remaining challenges for it to climb the space vertically, which puts its trade profile more in line with that typical of other developing countries.

Future research will have to devise empirical methods to better capture the extent of production sharing and supply-chain trade. Revealed comparative indicators reliant on net trade flows alone are not suitable for capturing the phenomenon of international production fragmentation. These indicators do not allow for a clear separation of the imported portion of capabilities embodied in the intermediate goods a country exports after further processing or assembly. Only an explicit distinction of trade in parts and components from trade in final goods, thus of value-added trade essentially, would provide a reliable basis to assess countries' net capabilities. Efforts in this direction are underway, and are likely to lead to important revisions concerning the assessment of capabilities with regard to processing hubs whose exports rely most heavily on imported components, such as is the case of China. 


\section{REFERENCES}

ADB-ILO-IDB (2010), "Indonesia-Critical Development Constraints", Country Diagnostic Studies, Asian Development Bank, International Labor Organization, and Islamic Development Bank. Mandaluyong City, Philippines. http://www.adb.org/Documents/Studies/indonesia-criticaldevelopment-constraints/main-report-Indonesia-Critical-Development-Constraints/indonesia-criticaldevelopment-constraints.pdf.

Alessandrini, M., B. Fattouh, B. Ferrarini and P. Scaramozzino (2011), "Tariff Liberalization and Trade Specialization: Lessons from India", Journal of Comparative Economics, forthcoming.

Athukorala P. and N. Yamashita, 2006. Production Fragmentation and Trade Integration: East Asia in a Global Context. The North American Journal of Economics and Finance, 17(3), 233-256

Arndt, Sven and Kierzkowski, Hendrick, 2001. Fragmentation: new production patterns in the world economy, Oxford University Press, ISBN 9780199243310.

Balassa, B. (1986), "Comparative Advantage in Manufactured Goods: A Reappraisal", Review of Economics and Statistics, Vol. 68, No. 2, May, pp. 315-319.

Baldwin, R. (2006), "Globalisation: The Great Unbundling (s)," Prime Minister's Office-Economic Council of Finland, 20 September 2006.

Baldwin, R. (2012), "Global Supply Chains: Why They Emerged, Why They Matter, and Where They Are Going", CEPR Discussion Papers, DP9103.

Brülhart, M. (2009): "An Account of Global Intra-Industry Trade, 1962-2006," The World Economy, Vol. 32, No. 3, pp. 401-459.

Bugamelli, M. (2001), "Il Modello di Specializzazione Internazionale dell'Area dell'Euro e dei Principali Paesi Europei: Omogeneità e Convergenza", Temi di Discussione 402, Banca d'Italia, Rome.

Dedrick, J., Kraemer, K. and G. Linden (2010): "Who profits from innovation in global value chains?: a study of the iPod and notebook PCs", Industrial and Corporate Change, 19 (1), pp. 81-116

Ferrarini, 2013. Vertical Trade Maps. Asian Economic Journal, vol. 27(2), 105-123.

Fontagné, L., M. Freudenberg and G. Gaulier (2006), "A Systematic Decomposition of World Trade into Horizontal and Vertical IIT", Review of World Economics, Vol. 142, No. 3, pp. 459-475.

Fontagné, L., G. Gaulier and S. Zignago, "Specialization across varieties and North-South competition", Economic Policy, January 2008, pp.5-49

Fujita, M., P. Krugman and A. J. Venables (1999), The Spatial Economy: Cities, Regions and International Trade, Cambridge (MA), The MIT Press.

Gaulier, G., and S. Zignago (2010), "BACI: International Trade Database at the Product-level. The 1994-2007 Version", CEPII, Centre d'Etudes Prospectives et d'Informations Internationales", Working Paper No. 2010-23, October.

Greenaway, D., and C. R. Milner (2003), "What Have We Learned from a Generation's Research on Intra-Industry Trade?", GEP Leverhulme Centre, University of Nottingham, Research Paper 2003/44. 
Greenaway, D., and J. Torstensson (1997), "Back to the Future: Taking Stock on Intra-Industry Trade”, Weltwirtschaftiches Archiv, Vol. 133, No. 2, pp. 249-269.

Hausmann, R., J. Hwang and D. Rodrik (2007), "What You Export Matters", Journal of Economic Growth, Vol. 12, pp. 1-25.

Hausmann, R., and B. Klinger (2006), "Structural Transformation and Patterns of Comparative Advantage in the Product Space", Centre for International Development, Harvard University, Working Paper No. 128.

Hausmann, R., and B. Klinger (2007), "The Structure of the Product Space and the Evolution of Comparative Advantage", Centre for International Development, Harvard University, Working Paper No. 146.

Hidalgo, C. A. (2009), "The Dynamics of Economic Complexity and the Product Space over a 42 Year Period", Centre for International Development, Harvard University, Working Paper No. 189.

Hidalgo, C. A., and R. Hausmann (2009), "The Building Blocks of Economic Complexity", Proceedings of the National Academy of Sciences, Vol. 106, No. 26, June 30, pp. 10570-10575.

Hidalgo, C. A., B. Klinger, A.-L. Barabási, and R. Hausmann (2007), "The Product Space Conditions the Development of Nations", Science, Vol. 317, 27 July, pp. 482-487.

Hirschman, A. (1958), The Strategy of Economic Development, New Haven, Conn., Yale University Press.

Iapadre, P. L. (2001), "Measuring International Specialization”, International Advances in Economic Research, Vol. 7, No. 2, May.

Lafay, G. (1992), “The Measurement of Revealed Comparative Advantage”, in M. G. Dagenais and P. A. Muet (eds), International Trade Modelling, London, Chapman \& Hall.

Leamer, E. (1984), Sources of International Comparative Advantage: Theory and Evidence, Cambridge, MA: MIT Press.

Schott, P. K. (2004), "Across-Product versus Within-Product Specialization in International Trade", Quarterly Journal of Economics, Vol. 119, No. 2, May, pp. 647-678.

Schott, P. K. (2008), “ The relative sophistication of Chinese exports”, Economic Policy, January 2008, pp.5-49

Shaked, A., and J. Sutton (1984), "Natural Oligopolies and International Trade", in H. Kierzkowski (ed.), Monopolistic Competition and International Trade, Oxford, Oxford University Press.

Shannon P., A. Markiel, O. Ozier, N.S. Baliga, J.T. Wang, D. Ramage, N. Amin, B. Schwikowski and T. Ideker (2003), "Cytoscape: A Software Environment for Integrated Models of Biomolecular Interaction Networks", Genome Research, Vol. 13, No. 11, November, pp. 2498-2504.

Sutton, J. (1986), "Vertical Product Differentiation: Some Basic Themes", American Economic Review, Vol. 76, No. 2, Papers and Proceedings, May, pp. 393-398.

Sutton, J. (1998), Technology and Market Structure: Theory and History, Cambridge (MA), The MIT Press.

Sutton, J. (2001), "Rich Trades, Scarce Capabilities: Industrial Development Re-visited", Keynes Lecture, British Academy, 2000, Proceedings of the British Academy 2001. 
Zaghini, A. (2005), "Evolution of Trade Patterns in the New EU Member States", Economics of Transition, 13(4), 629-658. 


\section{APPENDIX: CHARTS and TABLES}

Data Appendix

Trade data are drawn from the BACI dataset by the Centre d'Etudes Prospectives et d'Informations Internationales (CEPII). ${ }^{15}$ Constructed on the basis of raw data from UN Comtrade, the BACI dataset offers the advantage of broad coverage of trade flows measured in volume, obtained through mirroring techniques of trade flow data available from UN Comtrade partner countries' records. Therefore, the BACI dataset is particularly suitable for the analysis of unit value data, which is one purpose of this paper's expansion of the unit values concept. The data are disaggregated to six digits of the Harmonized System. For the analysis, we use data alternatively at 6 and 4 digits of aggregation.

Population and GDP per capita series in purchasing power parity are obtained from the World Bank's World Development Indicators (WDI), accessed online in August 2010. Data for Taipei, China, where added from official country statistics, since missing in World Bank statistics. To reduce possible noise deriving from the inclusion of very small, countries with populations totaling less than 1 million were dropped from the database prior to computations.

Data availability in the BACI HS1996 database spans from 1998 to $2007 .{ }^{16}$ For this analysis, we used the datasheet for the year 2007 only, leaving the analysis of the historical evolution of the product space for future analysis.

\footnotetext{
${ }^{15}$ For a description of the dataset, see http://www.cepii.fr/anglaisgraph/workpap/pdf/2010/wp2010-23.pdf

${ }^{16}$ There is another version of BACI, HS1992, available for analysis, according to a previous nomenclature of HS and spanning from 1995 to 2009 .
} 
TABLE 1.

Trade specialization indicators: Balassa index (HS4)

\begin{tabular}{lcccccccc}
\hline \multirow{2}{*}{ Country } & \multicolumn{2}{c}{ Unit Values } & & \multicolumn{4}{c}{ PRODY } & \multirow{2}{*}{ Whole sample } \\
\cline { 2 - 3 } \cline { 6 - 8 } & Low & High & & Q1 & Q2 & Q3 & Q4 & \\
\hline China & 2.74 & 1.79 & & 2.60 & 3.02 & 2.47 & 1.62 & 2.56 \\
United States & 1.80 & 1.80 & & 1.45 & 1.79 & 1.77 & 2.02 & 1.80 \\
All Countries & 6.61 & 5.11 & & 17.31 & 3.10 & 1.90 & 1.26 & 5.89 \\
\hline
\end{tabular}

PRODY = productivity index

Note: PRODY is computed as in equation (2); Q1-Q4 denote the quartiles of the PRODY distribution.

Source: Author's calculations.

TABLE 2A.

Balassa vs. Lafay: Pearson and Spearman correlation coefficients (HS 4 digits)

\begin{tabular}{|c|c|c|c|c|c|c|c|}
\hline & \multicolumn{2}{|c|}{ Unit Values } & \multicolumn{4}{|c|}{ PRODY } & \multirow{2}{*}{$\begin{array}{l}\text { Whole } \\
\text { sample }\end{array}$} \\
\hline & Low & High & Q1 & Q2 & Q3 & Q4 & \\
\hline Pearson & 0.1879 & 0.0834 & 0.2242 & 0.0754 & 0.1401 & 0.2349 & 0.1399 \\
\hline Spearman & 0.5696 & 0.4810 & 0.6406 & 0.5522 & 0.4753 & 0.4165 & 0.5257 \\
\hline
\end{tabular}

Note: PRODY is computed as in equation (2); Q1-Q4 denote the quartiles of the PRODY distribution.

Source: Author's calculations.

TABLE 2B.

Spearman's rank correlation coefficients

\begin{tabular}{clc}
\hline HS digits & Country & Spearman's $\rho$ \\
\hline 4 & China & 0.7028 \\
6 & China & 0.6947 \\
& & \\
4 & United States & 0.7207 \\
6 & United States & 0.7073 \\
\hline
\end{tabular}

$P R O D Y=$ productivity index

Source: Author's calculations. 
TABLE 3A.

Average proximity according to Unit Values and to the absolute difference between PRODY quartiles (4-digits)

\begin{tabular}{cccc}
\hline Absolute difference between & \multicolumn{3}{c}{ Unit Value Combinations } \\
\cline { 2 - 4 } PRODY quartiles & HH & HL & LL \\
\hline 0 & 0.26 & 0.22 & 0.25 \\
1 & 0.25 & 0.22 & 0.24 \\
2 & 0.24 & 0.21 & 0.22 \\
3 & 0.23 & 0.19 & 0.19 \\
\hline
\end{tabular}

Note: HH denotes that both products are high- $U V$ relative to the median, LL that both products are low$U V$, and HL that one of the two products is high- $U V$ and the other is low- $U V$.

$P R O D Y=$ productivity index

Source: Author's calculations.

TABLE 3B.

Average proximity according to Unit Values and to the absolute difference between $P R O D Y$ quartiles (6-digits)

\begin{tabular}{cccc}
\hline Absolute difference between & \multicolumn{3}{c}{ Unit Value Combinations } \\
\cline { 2 - 4 } PRODY quartiles & HH & HL & LL \\
\hline 0 & 0.26 & 0.23 & 0.27 \\
1 & 0.26 & 0.22 & 0.26 \\
2 & 0.25 & 0.21 & 0.24 \\
3 & 0.22 & 0.19 & 0.21 \\
\hline
\end{tabular}

Note: $\mathrm{HH}$ denotes that both products are high- $U V$ relative to the median, LL that both products are low$U V$, and HL that one of the two products is high- $U V$ and the other is low- $U V$.

$P R O D Y=$ productivity index

Source: Author's calculations. 
FIGURE 1A.

PRODY and Cumulated Lafay Index, HS 4-digits - China

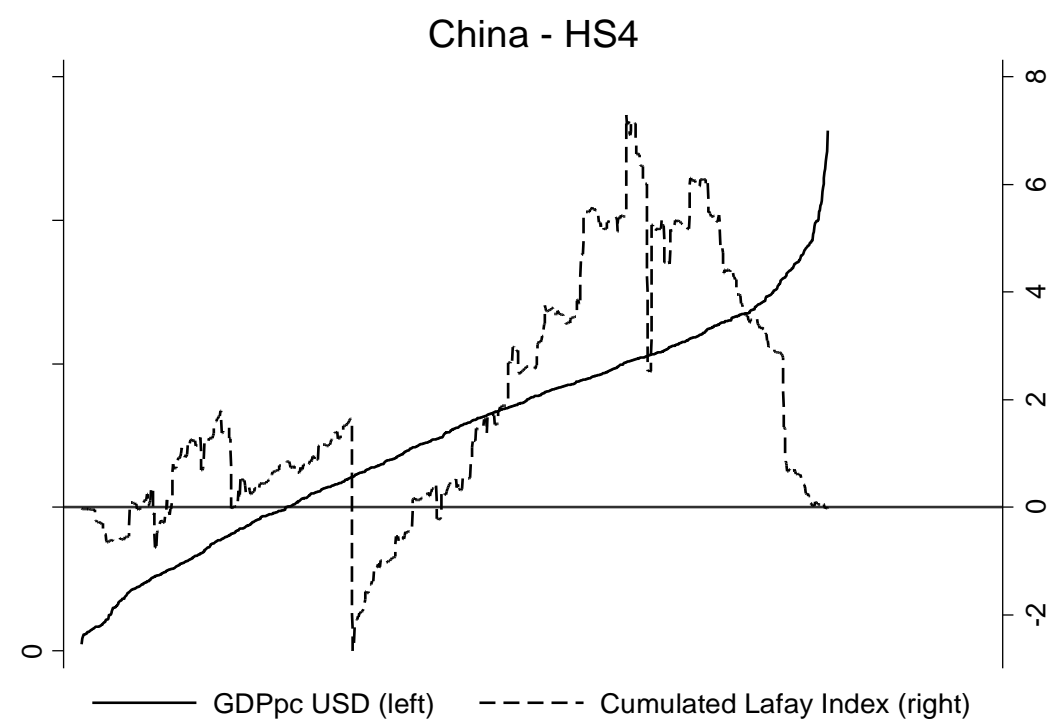

GDPpc USD $=$ Gross domestic product per capita in US dollars; HS = Harmonized System Source: Author's calculations.

FIGURE 1B.

PRODY and Cumulated Lafay Index, HS 4-digits - United States

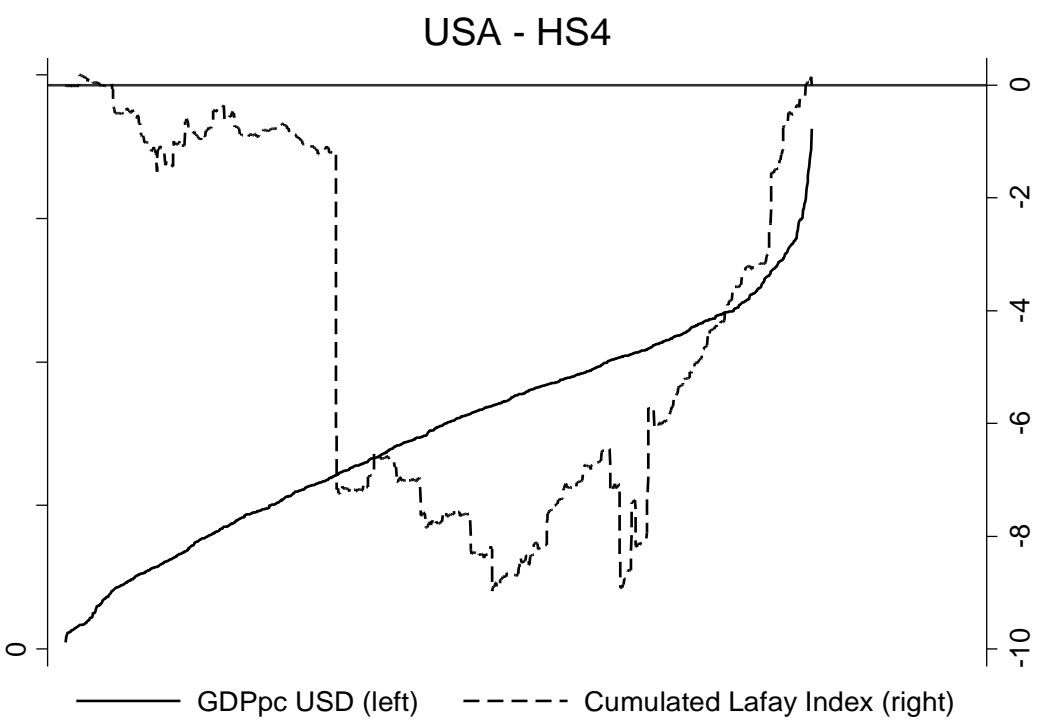

GDPpc USD = Gross domestic product per capita in US dollars; HS = Harmonized System Source: Author's calculations. 
FIGURE 2A.

The Product Space: Balassa Index - China

Product Space 2007

Balassa RCA

HS 4 digits

China

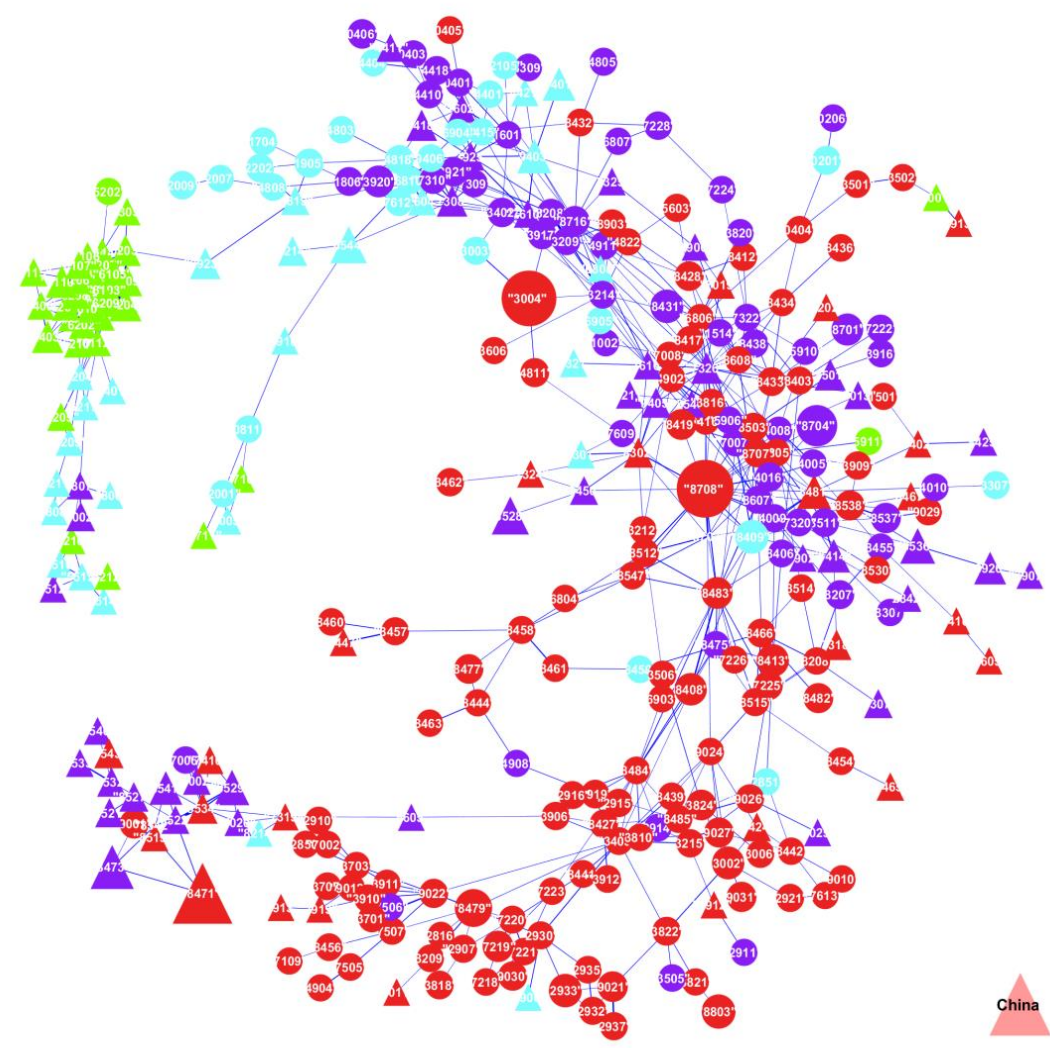

Legend

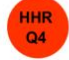

HS = Harmonized System; HHR = PRODY (productivity index)

Source: Author's calculations. 
FIGURE 2B.

The Product Space: Balassa Index - United States

Product Space 2007

Balassa RCA

HS 4 digits

USA

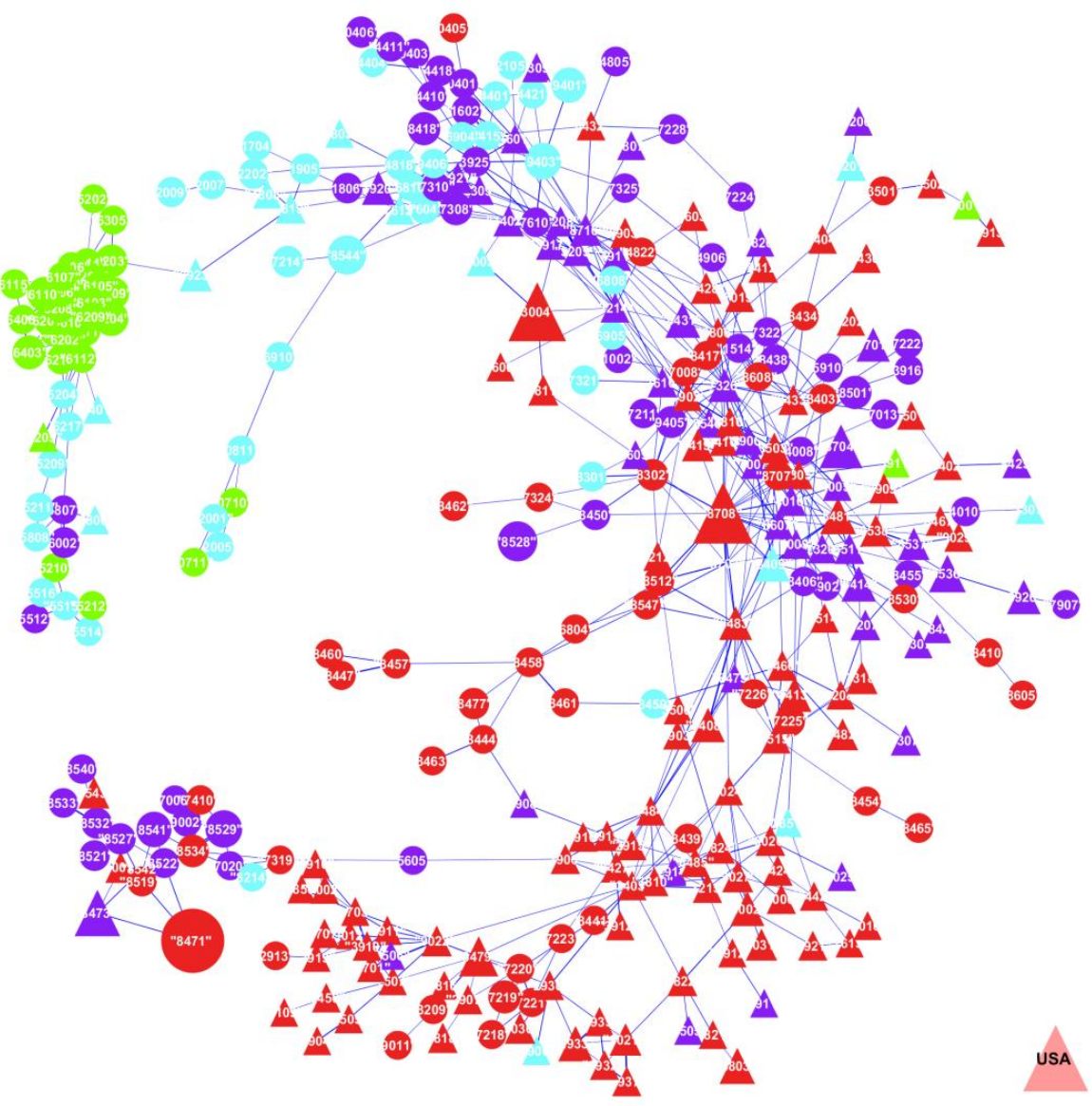

Legend
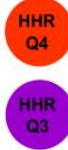

HS = Harmonized System; USA = United States; HHR = PRODY (productivity index $)$

Source: Author's calculations. 
FIGURE 3A.

The Product Space: Lafay Index - China

Product Space 2007

Lafay HS 4 digits

China

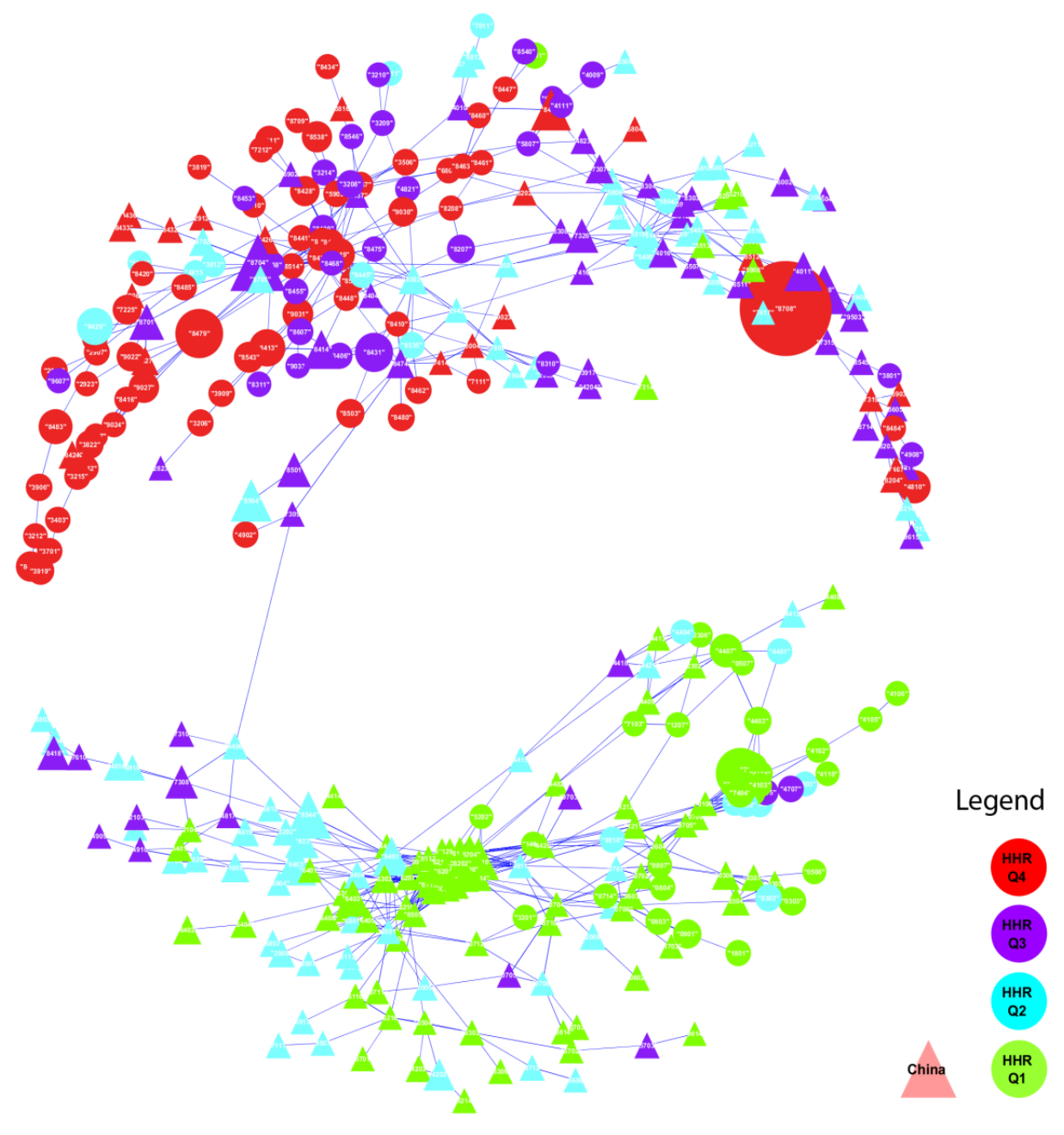

HS = Harmonized System; HHR = PRODY (productivity index)

Source: Author's calculations. 
FIGURE 3B.

The Product Space: Lafay Index - United States

Product Space 2007

Lafay RCA

HS 4 digits

USA
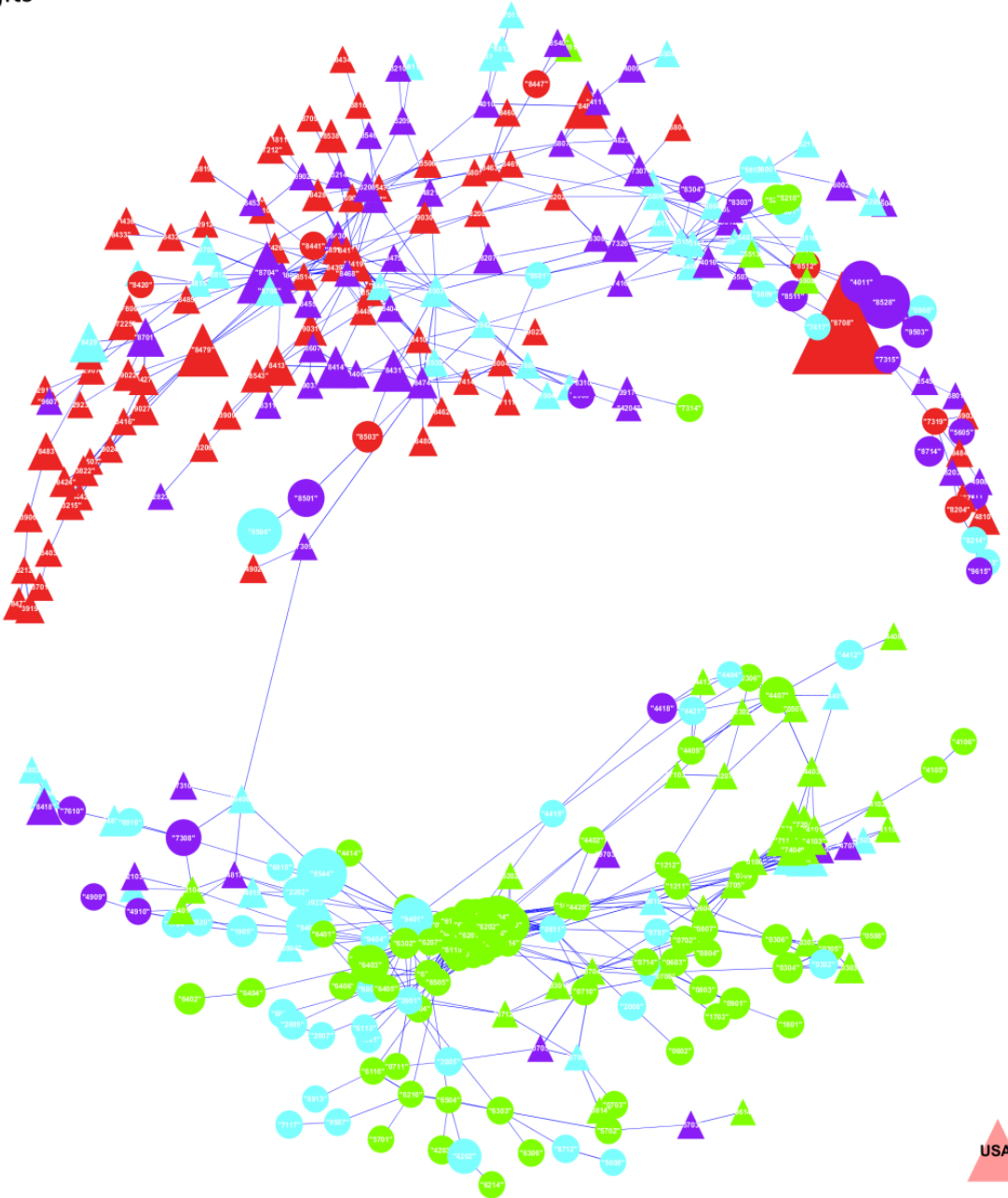

Legend

HS = Harmonized System $;$ USA = United States $;$ HHR $=$ PRODY (productivity index $)$ Source: Author's calculations. 
FIGURE 4A.

PRODY and Cumulated Lafay Index, HS 4-digits, Low Unit Values - China

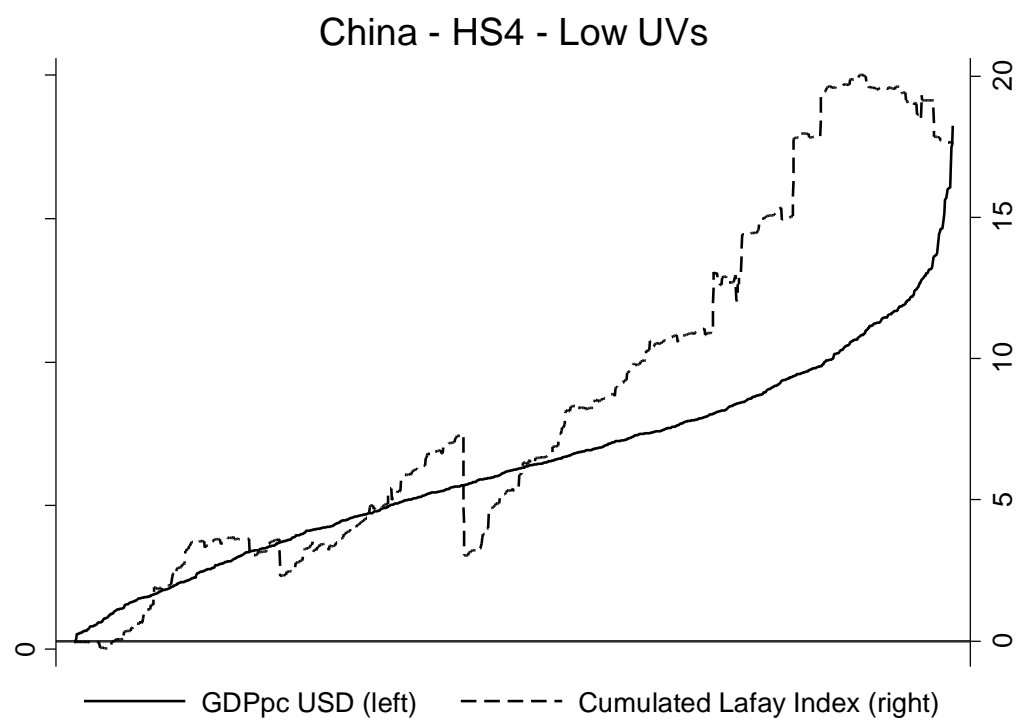

GDPpc USD = Gross domestic product per capita in US dollars; HS = Harmonized System; PRODY = productivity index; $\mathrm{UV}=$ unit value

Source: Author's calculations.

FIGURE 4B.

PRODY and Cumulated Lafay Index, HS 4-digits, High Unit Values - China.

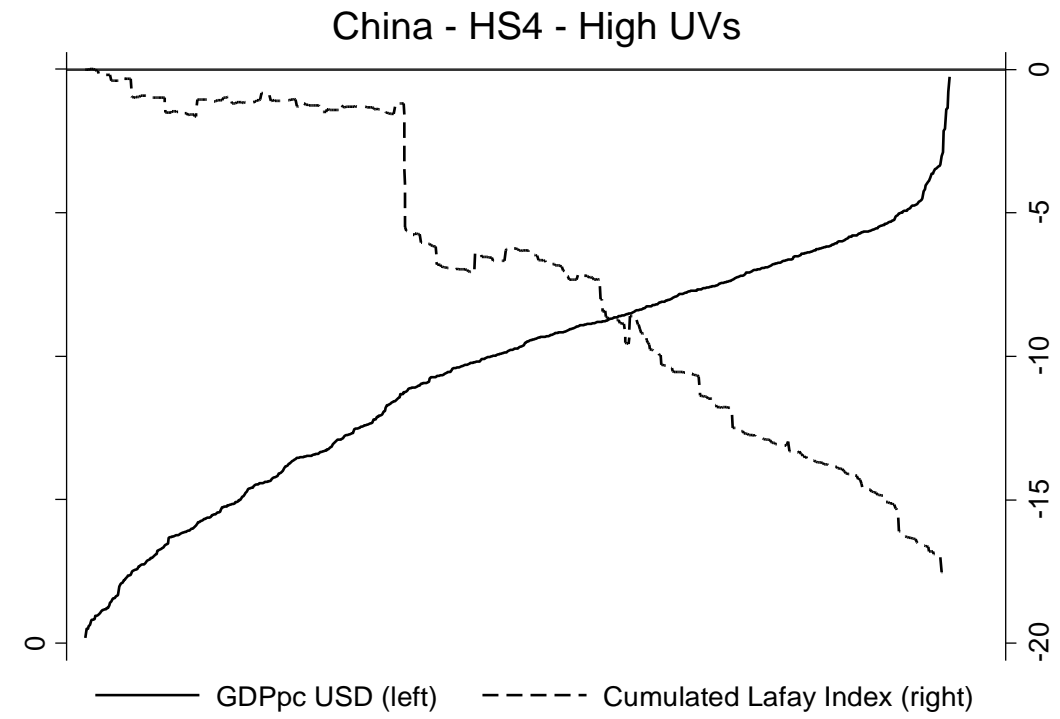

GDPpc USD = Gross domestic product per capita in US dollars; HS = Harmonized System; PRODY = productivity index; $\mathrm{UV}=$ unit value

Source: Author's calculations. 


\section{FIGURE 5A.}

PRODY and Cumulated Lafay Index, HS 4-digits, Low Unit Values - United States

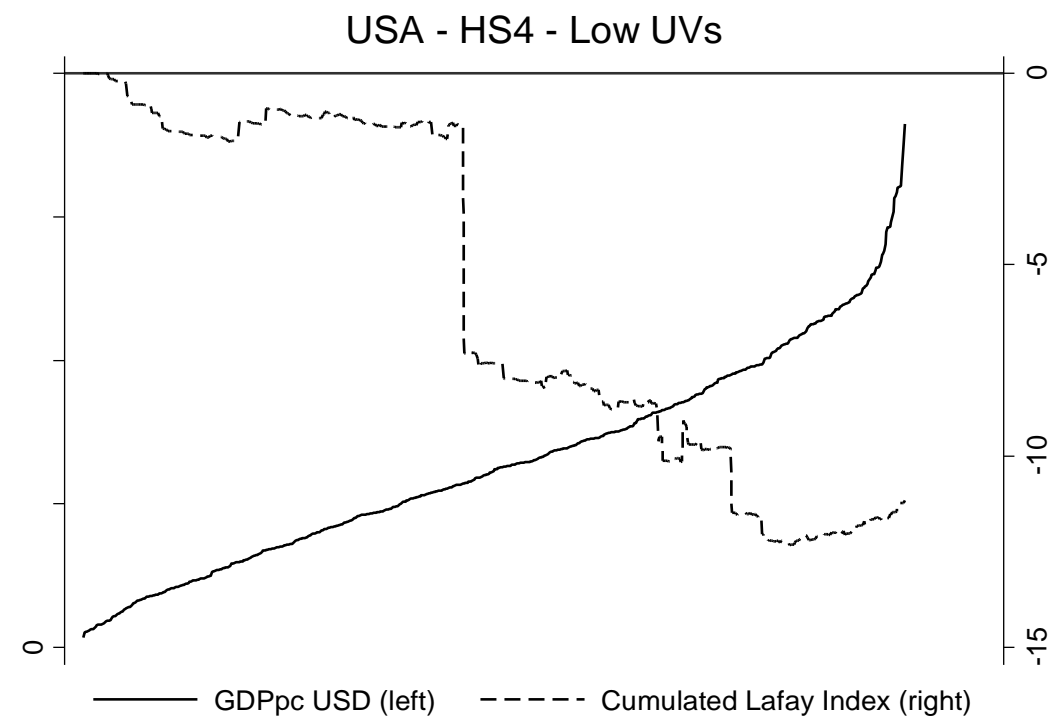

GDPpc USD = Gross domestic product per capita in US dollars; HS = Harmonized System; PRODY = productivity index; USA = United States; UV = unit value

Source: Author's calculations.

FIGURE 5B.

PRODY and Cumulated Lafay Index, HS 4-digits, High Unit Values - United States

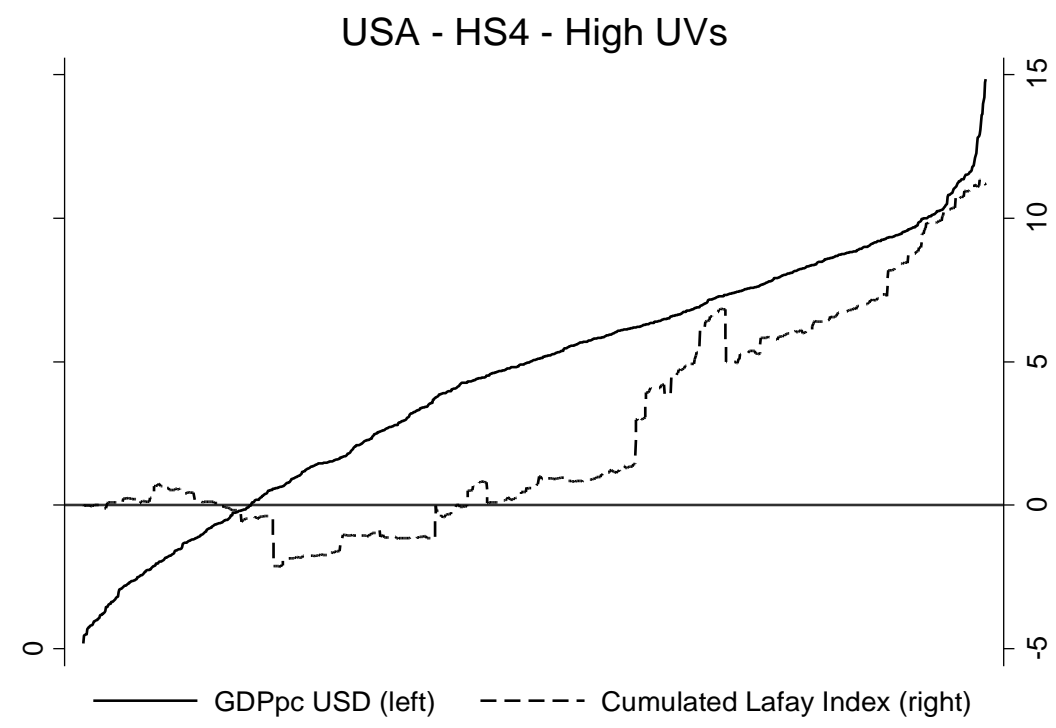

GDPpc USD = Gross domestic product per capita in US dollars; HS = Harmonized System; PRODY = productivity index; USA = United States; UV = unit value Source: Author's calculations. 